\title{
Biopsychosocial impact of prostate cancer and androgen-deprivation therapy
}

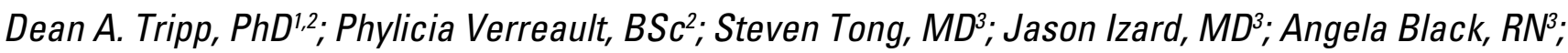 \\ D. Robert Siemens, $M D^{3,4}$
}

'Department of Psychology, Anesthesiology and Urology; ${ }^{2}$ Department of Psychology; ${ }^{3}$ Department of Urology; ${ }^{4}$ Department of Anesthesiology \& Perioperative Medicine; Queen's University, Kingston, ON, Canada

Cite as: Can Urol Assoc J 2017;11(10):338-43. http://dx.doi.org/10.5489/cuaj.4499

\section{Abstract}

Introduction: Prostate cancer is the most non-cutaneous malignancy in men, and androgen-deprivation therapy (ADT) is a cornerstone of management in advanced disease. The aim of this study was to evaluate the association of ADT with changes in depression and mental and physical quality of life (QoL) within a prospective patient cohort design.

Methods: Patients were prospectively recruited and consented at a single academic health sciences centre in Ontario, Canada. Inclusion criteria included those men with adenocarcinoma of the prostate and either on watchful waiting or initiating ADT as palliation or as an adjuvant therapy for high-risk localized disease. All three cohorts were followed in routine care and completed psychosocial evaluations, including depression, social support, anxiety, and QoL measures.

Results: In comparison to the control cohort of patients with prostate cancer on watchful waiting, initiation of ADT over a two-year period of time was not associated with any changes in depression or mental QoL. Instead, all patients, regardless of treatment cohort, showed increased depression scores and reduced mental QoL scores over time; however, for patients receiving ADT, a significant reduction in physical QoL compared to patients who did not receive ADT was demonstrated.

Conclusions: ADT does not appear to significantly impact depressive symptoms and mental QoL over a two-year period; however, the depressive symptoms in this limited sample of men with prostate cancer was higher than expected and monitoring for these may be advisable for those who care for such patients.

\section{Introduction}

Prostate cancer is the most common non-cutaneous malignancy and the second leading cause of cancer-related death of men in North America. ${ }^{1}$ Androgen-deprivation therapy (ADT) remains a cornerstone of management of advanced disease; ADT improves survival when used in combination with radiotherapy in men with high-risk localized cancer, and represents standard palliation for men with incurable disease..$^{2-4}$ Despite the cancer-related benefits, ADT has been well-shown to be associated with short- and long-term adverse effects, including sexual dysfunction, fatigue, hot flashes, osteoporosis, and cardiovascular complications. ${ }^{5}$ There is increasing evidence that ADT may also impact the psychological well-being of prostate cancer patients; ${ }^{6,7}$ however, there are conflicting results in the literature as to the impact of ADT on depression. Many studies that have implicated ADT in depression either did not use validated depression-specific questionnaires or did not include control groups with patients suffering from prostate cancer and not receiving treatment. Thus, we sought to determine the impact of ADT on depression and mental and physical quality of life (QoL) in patients with both local and advanced disease using a prospective cohort study. We also wanted to determine the predictors of mental and physical QoL in men with prostate cancer.

\section{Methods}

\section{Participants}

Participants were recruited from a single academic health sciences centre in Kingston, ON, Canada. The study was approved by the Health Sciences and Affiliated Teaching Hospitals Research Ethics Board of Queen's University. Participants were men with clinically confirmed prostate cancer and were included in one of the three groups for this prospective cohort study: those undergoing palliative ADT for non-curative intent $(n=26)$; those with adjuvant/ neoadjuvant ADT and radiotherapy for higher-risk localized disease $(n=20)$; and those undergoing watchful waiting $(n=19)$. ADT-treated groups were enrolled at least four weeks prior to the initiation of ADT. The exclusion criteria included another active malignancy, major neuropsychiatric disorder, physically unable to attend appointments, or previous severe depression requiring hospitalization. Baseline measures included questionnaire (described below) and com- 
plete bloodwork before treatment. Patients receiving ADT were given oral bicalutamide for a month and then received injection of luteinizing hormone-releasing hormone (LHRH) agonist. Followup measures included questionnaire and bloodwork every three months during two-year followup for a total of nine time points.

\section{Measures}

\section{Demographic questionnaire}

The demographic questionnaire included questions about age, weight, height, ethnicity, marital and employment status, smoking habits, alcohol consumption habits, family history of prostate cancer, number of psychological and/ or physical adverse events during the course of treatment (e.g., flu, headaches, death of relative), medication intake, and medical visits.

\section{Centre for Epidemiological Studies-Depression (CES-D)}

The CES-D is a 20-item questionnaire evaluating depressive symptoms during the past week that is rated on a four-point Likert-type scale. ${ }^{8}$ The range of possible values is 0 to 60 , with higher scores indicating more depressive symptomatology. The cutoff score for clinical depression is 16 or higher. The questionnaire has a good sensitivity and specificity, and was validated for the older adult population. ${ }^{9}$

\section{Short-form health survey-12 items (SF-12)}

The SF-12 is a 12-item measure of subjective functional health and well-being. ${ }^{10}$ It contains two subscales of six items each that create a mental QoL and physical QoL score, where higher scores indicate greater QoL. The reliability of the physical and mental component scales is 0.88 and 0.82 , respectively, indicating a high reliability of the SF-12. ${ }^{11}$

\section{State-Trait Anxiety Inventory}

The Spielberger State-Trait Anxiety Inventory has two components: the State Inventory and the Trait Inventory. ${ }^{12}$ The State Inventory (STAI-S) measures how much anxiety someone experiences at that moment. The Trait Inventory (STAI-T) measures how much anxiety someone experiences in general. All items are rated on a four-point Likert scale and higher scores indicates higher levels of anxiety.

\section{Pain Catastrophizing Scale (PCS)}

The PCS is a 13-item questionnaire assessing thoughts and feelings about the patient's pain. ${ }^{13}$ Each item is rated on a five-point Likert scale. The total score ranges from 0 to 52 , with higher scores indicating higher catastrophizing.

\section{Multidimensional Scale of Perceived Social Support (MSPSS)}

The MSPSS assesses the patient's perceived social support. ${ }^{14}$ In contains 12 statements that are rated on a seven-point Likert scale. The MSPSS contains three subscales: perceived social support from family; perceived social support from friends; and perceived social support from significant other. Higher scores indicate higher levels of perceived social support.

\section{Biomarkers}

Serum biomarkers that were hypothesized to be related to depression ${ }^{15}$ in men initiating ADT were collected and included: total testosterone; C-reactive protein (CRP); cortisol; follicle-stimulating hormone (FSH); and luteinizing hormone $(\mathrm{LH})$. Given the mechanism of action of the gonadotropin-releasing hormone $(\mathrm{GnRH})$ agonists and the potential relationship between inflammatory processes, as well as the hypothalamic-pituitary-adrenal axis (HPAA) and depression, ${ }^{15}$ we collected these markers at baseline, as well as during followup to interrogate any predictive ability for the depression or QoL measures.

\section{Design and data analyses}

This study was a prospective cohort design that used an intent-to-treat protocol. ${ }^{16}$ Analyses were performed with SPSS Statistics version 24.0, with all $p$ values set at 0.05 . Data were cleaned and all outliers $( \pm 3$ standard deviation [SD]) were replaced with the minimum or maximum value for the specific variable. Independent sample t-tests and Chisquare analyses were used to examine demographics. For the first ANOVA analyses, a mixed design ANOVA was conducted for each outcome variable of interest (i.e., depression, mental and physical QoL) for a total of three models. For each model, the outcome variable was entered as a within-subject factor for the nine assessment points. The between subject factor was the treatment group (i.e., palliative ADT, adjuvant ADT, watchful waiting control). For the second set of analyses, hierarchical multiple regressions were used to predict mental QoL and physical QoL.

\section{Results}

This study included 66 participants, with one removed from the analyses due to significant amounts of missing data. Demographics are presented in Table 1. Independent sample t-tests indicated that participants in the palliative hormone therapy group were slightly older (mean 74.8 years) than participants in the watchful control group (mean 69.3 years), but not different than participants in the adjuvant therapy group (mean 72.7 years). Independent sample t-tests indicated no differences in length since the diagnosis between groups. The participants in the two ADT groups (mean 6.6) were statistically taking more medication than participants in the control group (mean 4.5). Chi-square analyses indicated that participants in the three cohorts did not differ in terms of ethnicity, employment status, marital status, aller- 


\begin{tabular}{|c|c|c|c|}
\hline & $\begin{array}{c}\text { Palliative } \\
\text { ADT } \\
n=26\end{array}$ & $\begin{array}{c}\text { Adjuvant } \\
\text { ADT } \\
n=20\end{array}$ & $\begin{array}{c}\text { Watchful } \\
\text { waiting } \\
n=19\end{array}$ \\
\hline Age & $74.7(10.8)$ & $72.7(7.9)$ & $69.3(7.3)$ \\
\hline Length of diagnosis & $2.8(5.1)$ & $5.7(5.6)$ & $5.6(4.2)$ \\
\hline \multicolumn{4}{|l|}{ Ethnicity (\%) } \\
\hline Caucasian & 100.0 & 94.1 & 93.3 \\
\hline Black/African-Canadian & 0 & 0 & 6.7 \\
\hline Other & 0 & 5.9 & 0 \\
\hline \multicolumn{4}{|l|}{ Marital status (\%) } \\
\hline Married & 72.7 & 88.9 & 88.2 \\
\hline Divorced & 9.1 & 11.1 & 0 \\
\hline Widowed & 18.2 & 0 & 11.8 \\
\hline \multicolumn{4}{|l|}{ Employment (\%) } \\
\hline Yes & 50.0 & 41.2 & 52.9 \\
\hline No & 50.0 & 58.8 & 47.1 \\
\hline \multicolumn{4}{|l|}{ Smoking history (\%) } \\
\hline Never smoked & 38.9 & 20.0 & 21.4 \\
\hline Passive smoker & 55.6 & 66.7 & 71.4 \\
\hline Past smoker & 0 & 0 & 0 \\
\hline Present smoker & 5.6 & 13.3 & 7.1 \\
\hline \multicolumn{4}{|l|}{ Alcohol consumption (\%) } \\
\hline Abstainer & 23.5 & 21.4 & 23.1 \\
\hline Light & 58.8 & 57.1 & 53.8 \\
\hline Moderate & 17.6 & 14.3 & 23.1 \\
\hline Heavy & 0 & 7.1 & 0 \\
\hline
\end{tabular}

gies, smoking history, alcohol consumption, and level of clinical depression at baseline.

\section{Crossover}

A total of three participants changed study group during the study period. For the subsequent ANOVA analyses, participants remained in their original group, but their data was entered in an intent-to-treat from the time they crossed to palliative ADT group (at T5, T7, and T8, respectively) to avoid impact of the new therapy on the data.

\section{Mixed-model ANOVAs}

\section{Depression}

There was a significant main effect of time $F(8,496)=7.90$ $(p<0.001)$, but no main effect of group $F(2,62)=2.73(p=0.07)$ and no interaction of group and time $F(16,496)=0.42(p>0.05$.) These results indicate that the men in this study did report greater depression over the course of the assessments, but also that there were no group differences in depression scores (Table 2). Simple contrasts indicated that depression scores decreased from baseline within the first year $F(1,62)=31.45$ $(p<0.05)$, but increased again at 18 months and are significantly higher than baseline at 24 months $F(1,62)=4.86(p<0.05)$.

\section{Mental QoL}

There was a significant main effect of time $F(8,496)=10.19$ $(p<0.001)$, but no main effect of group $F(2,62)=0.83(p=0.44)$ and no group and time interaction $F(16,496)=0.75$ ( $p>0.05)$. Similar to depression scores, the three groups reported a worsening of mental QoL scores overtime, but no significant differences between groups (Table 2). Simple contrast indicated that starting at three months, mental QoL decreased significantly from baseline $F(1,62)=5.47(p<0.05)$.

\section{Physical Qol}

There was no significant main effect of time $F(8,496)=1.42$ $(p>0.05)$, but a significant main effect of group $F(2$, $62)=11.32(p<0.001)$ and no group and time interaction $F(16,496)=0.83(p>0.05)$. In contrast to the other analyses, physical QoL scores remained stable in the three groups over time, but the watchful waiting control group had significantly better physical QoL, followed by the adjuvant ADT group, with the palliative ADT group reporting the most diminished physical QoL (Table 2).

\section{Regressions}

Two-year mental and physical QoL were correlated with baseline mental QoL and physical QoL, the baseline biomarkers, and the baseline biopsychosocial variables (Table 3). Two-year mental QoL was correlated with baseline mental QoL, testosterone levels, and state anxiety. Two-year physical QoL was correlated with CRP, total medication intake, length of diagnosis, and state anxiety. The significant variables were included in the regression models respectively. Because of the high correlation between two-year physical QoL and baseline QoL, baseline physical QoL was removed from this regression model. Study group was included in physical QoL since it was shown to be different across groups in our previous ANOVA models.

\section{Mental QoL}

Biological factors were entered in the first step of the regression (Table 4) and were significant $\left(R^{2}=0.11 ; F(2,62)=5.05\right.$; $\mathrm{p}<0.05)$. The psychological variables entered in the second step of the regression were also significant $\left(R^{2}=0.16 ; F(1\right.$, $61)=4.14 ; p<0.05)$. Baseline testosterone and state anxiety were significant predictors of diminished two-year mental QoL in the final model.

\section{Physical Qol}

Study group was the sole significant predictor of diminished physical QoL $\left(R^{2}=0.26 ; F(3,54)=7.80 ; p<0.01\right)$ (Table 4). The psychological variable entered in Step 2 did not add to the prediction $\left(R^{2}=0.26 ; F(1,55)=0.64 ; p>0.05\right)$. 


\begin{tabular}{|c|c|c|c|c|c|c|c|c|c|}
\hline & \multicolumn{9}{|c|}{ Time (months) } \\
\hline & 0 & 3 & 6 & 9 & 12 & 15 & 18 & 21 & 24 \\
\hline \multicolumn{10}{|l|}{ Depression } \\
\hline Palliative ADT & $\begin{array}{l}13.04 \\
(6.74)\end{array}$ & $\begin{array}{c}8.88 \\
(6.08)\end{array}$ & $\begin{array}{l}11.50 \\
(6.83)\end{array}$ & $\begin{array}{c}10.81 \\
(10.39)\end{array}$ & $\begin{array}{c}9.85 \\
(6.94)\end{array}$ & $\begin{array}{c}12.31 \\
(10.86)\end{array}$ & $\begin{array}{c}12.19 \\
(10.95)\end{array}$ & $\begin{array}{c}13.42 \\
(11.20)\end{array}$ & $\begin{array}{c}16.42 \\
(12.00)\end{array}$ \\
\hline Adjuvant ADT & $\begin{array}{l}10.26 \\
(6.15)\end{array}$ & $\begin{array}{c}6.55 \\
(4.92)\end{array}$ & $\begin{array}{c}9.10 \\
(7.38)\end{array}$ & $\begin{array}{c}9.40 \\
(7.08)\end{array}$ & $\begin{array}{c}8.42 \\
(7.50)\end{array}$ & $\begin{array}{c}8.00 \\
(7.23)\end{array}$ & $\begin{array}{c}10.05 \\
(12.00)\end{array}$ & $\begin{array}{c}10.60 \\
(12.63)\end{array}$ & $\begin{array}{c}13.00 \\
(13.07)\end{array}$ \\
\hline Watchful waiting & $\begin{array}{c}8.89 \\
(6.14)\end{array}$ & $\begin{array}{c}5.79 \\
(6.23)\end{array}$ & $\begin{array}{c}5.95 \\
(4.72)\end{array}$ & $\begin{array}{c}6.20 \\
(6.53)\end{array}$ & $\begin{array}{c}6.26 \\
(6.08)\end{array}$ & $\begin{array}{c}6.05 \\
(5.59)\end{array}$ & $\begin{array}{c}7.32 \\
(6.33)\end{array}$ & $\begin{array}{c}6.70 \\
(5.95)\end{array}$ & $\begin{array}{r}12.53 \\
(11.01)\end{array}$ \\
\hline \multicolumn{10}{|l|}{ Mental QoL } \\
\hline Palliative ADT & $\begin{array}{l}53.98 \\
(6.99)\end{array}$ & $\begin{array}{l}51.30 \\
(7.63)\end{array}$ & $\begin{array}{l}52.12 \\
(8.27)\end{array}$ & $\begin{array}{l}51.08 \\
(7.84)\end{array}$ & $\begin{array}{l}49.88 \\
(8.78)\end{array}$ & $\begin{array}{l}48.50 \\
(9.26)\end{array}$ & $\begin{array}{l}49.18 \\
(8.75)\end{array}$ & $\begin{array}{l}47.90 \\
(9.37)\end{array}$ & $\begin{array}{l}48.27 \\
(9.03)\end{array}$ \\
\hline Adjuvant ADT & $\begin{array}{l}54.88 \\
(5.46)\end{array}$ & $\begin{array}{l}53.33 \\
(6.65)\end{array}$ & $\begin{array}{l}52.40 \\
(7.26)\end{array}$ & $\begin{array}{l}52.87 \\
(6.87)\end{array}$ & $\begin{array}{l}54.05 \\
(6.77)\end{array}$ & $\begin{array}{l}50.94 \\
(5.61)\end{array}$ & $\begin{array}{l}51.37 \\
(5.28)\end{array}$ & $\begin{array}{l}50.67 \\
(6.45)\end{array}$ & $\begin{array}{l}50.45 \\
(6.57)\end{array}$ \\
\hline Watchful waiting & $\begin{array}{l}56.55 \\
(4.64)\end{array}$ & $\begin{array}{l}54.67 \\
(6.66)\end{array}$ & $\begin{array}{l}53.84 \\
(6.84)\end{array}$ & $\begin{array}{l}53.11 \\
(7.07)\end{array}$ & $\begin{array}{l}51.99 \\
(7.87)\end{array}$ & $\begin{array}{c}50.57 \\
(60.40)\end{array}$ & $\begin{array}{l}47.97 \\
(7.82)\end{array}$ & $\begin{array}{l}48.64 \\
(8.24)\end{array}$ & $\begin{array}{l}48.98 \\
(8.00)\end{array}$ \\
\hline \multicolumn{10}{|l|}{ Physical QoL } \\
\hline Palliative ADT & $\begin{array}{c}41.09 \\
(10.63)\end{array}$ & $\begin{array}{l}41.95 \\
(9.36)\end{array}$ & $\begin{array}{l}40.66 \\
(9.56)\end{array}$ & $\begin{array}{l}39.86 \\
(9.25)\end{array}$ & $\begin{array}{l}38.96 \\
(9.44)\end{array}$ & $\begin{array}{l}38.65 \\
(9.65)\end{array}$ & $\begin{array}{l}38.67 \\
(9.36)\end{array}$ & $\begin{array}{l}38.13 \\
(9.85)\end{array}$ & $\begin{array}{l}37.91 \\
(9.98)\end{array}$ \\
\hline Adjuvant ADT & $\begin{array}{c}45.38 \\
(10.63)\end{array}$ & $\begin{array}{c}45.11 \\
(11.54)\end{array}$ & $\begin{array}{l}43.98 \\
(8.28)\end{array}$ & $\begin{array}{l}43.55 \\
(9.88)\end{array}$ & $\begin{array}{l}42.83 \\
(9.52)\end{array}$ & $\begin{array}{l}44.15 \\
(6.96)\end{array}$ & $\begin{array}{l}43.04 \\
(7.15)\end{array}$ & $\begin{array}{l}43.31 \\
(7.68)\end{array}$ & $\begin{array}{l}43.21 \\
(7.62)\end{array}$ \\
\hline Watchful waiting & $\begin{array}{l}49.54 \\
(8.32)\end{array}$ & $\begin{array}{l}48.94 \\
(6.92)\end{array}$ & $\begin{array}{l}50.57 \\
(5.92)\end{array}$ & $\begin{array}{l}51.33 \\
(4.54)\end{array}$ & $\begin{array}{l}50.22 \\
(7.52)\end{array}$ & $\begin{array}{l}49.57 \\
(4.11)\end{array}$ & $\begin{array}{l}50.30 \\
(4.61)\end{array}$ & $\begin{array}{l}49.54 \\
(5.52)\end{array}$ & $\begin{array}{l}49.55 \\
(5.53)\end{array}$ \\
\hline
\end{tabular}

\section{Discussion}

This study followed patients diagnosed with prostate cancer over two years and evaluated their depression, as well as mental and physical QoL. The results of this single-centre cohort indicated that patients who received ADT, either as adjuvant or palliative treatment, did not report significant elevations in depression compared to patients with a prostate cancer diagnosis on watchful waiting. With respect to QoL over the two-year period, there was no significant difference in mental QoL between treatment groups, and similar to depression, the scores of all three groups worsened over time; however, as expected, patients who received ADT demonstrated a significant reduction in physical QoL compared to patients who did not receive ADT. With regards to secondary outcomes, we found that diminished mental QoL was associated with base- line serum testosterone levels and state anxiety. These findings around the association between mental QoL and testosterone levels (prior to ADT) is of interest, given the ambiguity of previous investigations. ${ }^{15,17}$ We were unable to confirm any strong association of other HPAA biomarkers and depression in this cohort of men; however, our results are similar to the previous results demonstrating the importance of stress in predicting psychological functioning in men with prostate cancer. ${ }^{18}$ Moreover, the only predictor of physical QoL was group status. These specific results need to be considered with caution since the difference in physical QoL may be explained by the different disease stage and not the treatment received.

It is important to note that this sample of men with prostate cancer had higher depression scores than men in the general population, regardless of the treatment they received. The increase in mean depression scores in all three treatment

Table 3. Correlations between 2-year physical and mental quality of life, baseline biomarkers, and baseline biopsychosocial variables

\begin{tabular}{|c|c|c|c|c|c|c|c|c|c|c|c|c|c|c|}
\hline & \multicolumn{2}{|c|}{ Baseline QoL } & \multicolumn{4}{|c|}{ Biological variables } & \multicolumn{5}{|c|}{ Biomarkers } & \multicolumn{3}{|c|}{ Psychosocial variables } \\
\hline & Ment & Phys & Age & $\begin{array}{c}\text { Length } \\
\text { diag }\end{array}$ & $\begin{array}{c}\text { Med } \\
\text { use }\end{array}$ & AEs & CRP & FSH & LH & Test & Cort & PCS & MSPSS & $\begin{array}{c}\text { Anx } \\
\text { State }\end{array}$ \\
\hline $\begin{array}{l}\text { Mental } \\
\text { QoL 2-year }\end{array}$ & $0.28 *$ & 0.17 & -0.18 & 0.07 & -0.22 & -0.17 & -0.03 & 0.14 & 0.11 & $-0.31 *$ & -0.12 & -0.17 & 0.22 & $-0.32 *$ \\
\hline $\begin{array}{l}\text { Physical } \\
\text { QoL 2-year }\end{array}$ & 0.22 & $0.79 * *$ & -0.23 & $0.31^{*}$ & $-0.32^{*}$ & -0.15 & -0.23 & 0.19 & 0.18 & -0.17 & 0.10 & -0.18 & -0.04 & $-0.26^{*}$ \\
\hline
\end{tabular}

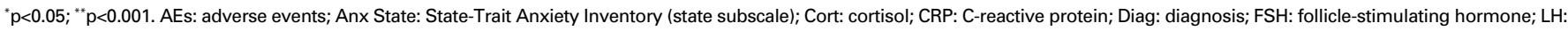

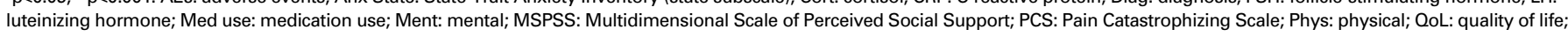
Test: testosterone. 


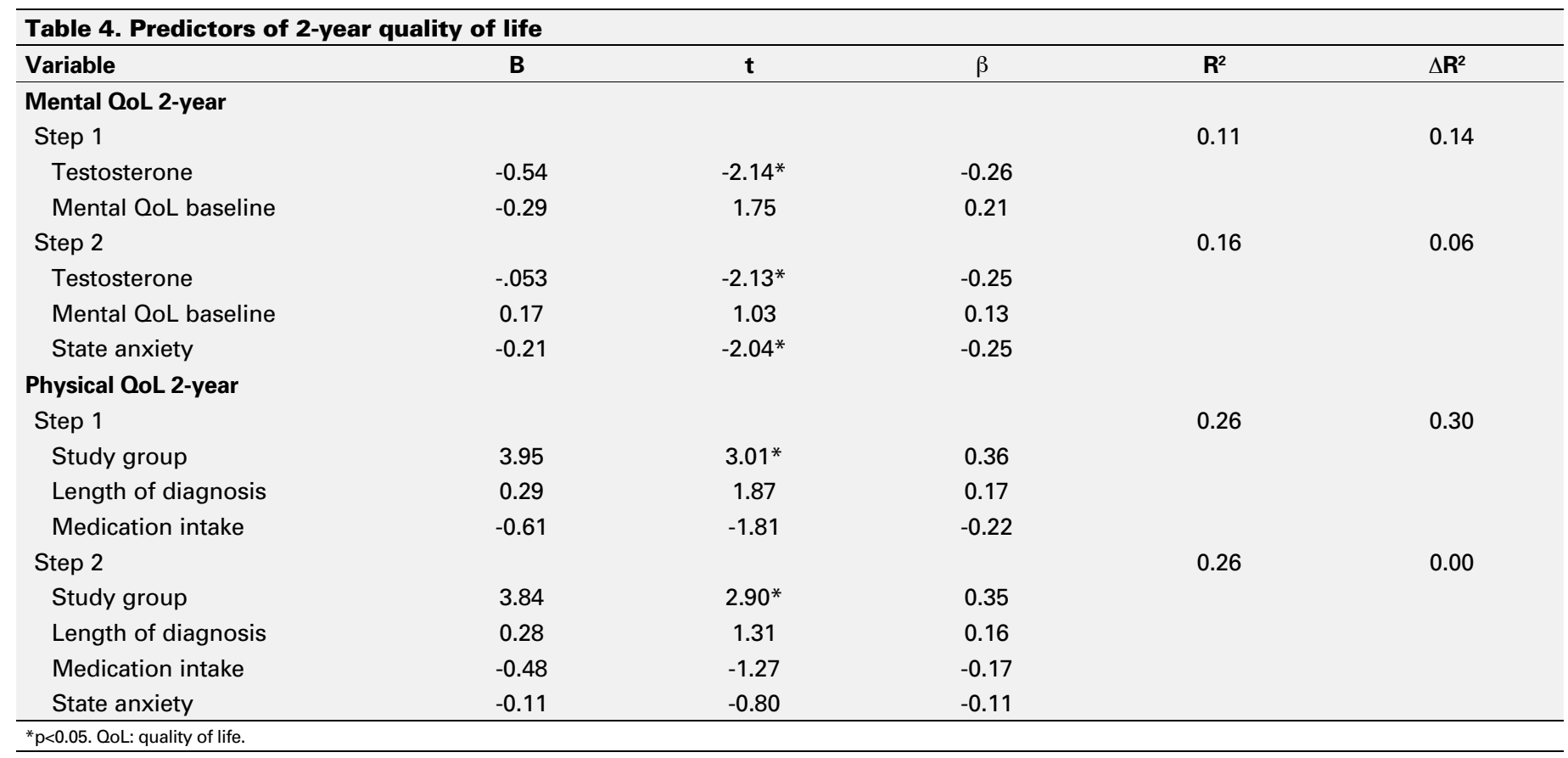

groups over time suggests a negative largescale effect of a prostate cancer diagnosis on psychological status, independent of ADT (Table 2). The high prevalence of depressive symptoms in the prostate cancer population can be a confounding factor for studies where the sample size may not provide sufficient power to elucidate a difference in the changes in depression scores between patients receiving ADT and those not receiving ADT. Moreover, since depression is an important factor in the prediction of future suicidality, and prostate cancer is a risk factor for suicide in older men, it may be especially important to address depressive symptoms in men diagnosed with advanced disease. ${ }^{19}$ Further research is needed on the depression/suicide association for men with prostate cancer and researchers should consider a fuller review of suicidal thoughts and behaviours within a longitudinal framework to aid in understanding initiators and outcomes.

Clinically, these results highlight the concern for patient psychological status in the treatment planning for men with prostate cancer. ${ }^{20}$ Patients with prostate cancer report a need for support services, such as information about offered services, educational brochures, and counselling. ${ }^{21} \mathrm{~A}$ recent evaluation of brief therapy using behavioural activation and problem-solving skills with breast cancer patients showed that following therapy, patients had significantly decreased depression and anxiety, and increased QoL. ${ }^{22}$ Similar programs adapted for prostate cancer have yet to be evaluated.

Although mental QoL had a global decline in all patient groups, a significant reduction in physical QoL was associated with ADT. While patients receiving ADT as adjuvant therapy had higher physical QoL scores than palliative patients, both groups scored lower compared to patients not receiving ADT.
This is not surprising, as it likely reflects the other associated adverse effects of ADT, including fatigue, decreased libido, and sarcopenia, among others. Indeed, ADT in advanced prostate cancer was previously associated with compromised physical function and decreased QoL.7 Alibhai et al, who reported an association with ADT and declines in both objective and selfreported physical function, echoed these results. ${ }^{23}$

While this study was able to examine the effect of ADT on depression and QoL of two different treatment modalities and with an untreated control group in a longitudinal design, there are limitations. First, the sample size of patients in each treatment arm and the contamination of treatment arms with patients who may have required further treatment during the study period reduces the statistical power and our ability to detect nuances between groups. Second, due to the patient population, most participants who were recruited identified as middle-class heterosexual white males. Whether the deleterious effects of ADT might be worse or lessened in patients of other socioeconomic status, sexual identity, or ethnicity is not explored.

\section{Conclusion}

Use of ADT in prostate cancer, either as adjuvant or palliative treatment, was not found to be associated with significant concomitant treatment spikes in depression or in mental QoL over a two-year time frame. Instead, all patients, regardless of treatment, showed increased depression scores and reduced mental QoL scores over time. Clinicians should consider the monitoring of depression a standard approach in prostate cancer patient care, regardless of treatment. 
Competing interests: The authors report no competing personal or financial interests.

Acknowledgement: This research was funded by the Masonic Foundation of Ontario.

This paper has been peer-reviewed.

\section{References}

1. Siegel RL, Miller KD, Jemal A. Cancer statistics, 2016. CA Cancer J Clin 2016;66:7-30. https://doi.org/10.3322/caac.21332

2. Bolla $M$, de Reijke $T M$, Van Tienhoven $G$, et al. Duration of androgen suppression in the treatment of prostate cancer. N Engl J Med 2009;360:2516-27. https://doi.org/10.1056/NEJMoa0810095

3. Horwitz $E M$, Bae K, Hanks GE, et al. Ten-year followup of radiation therapy oncology group protocol 92-02: A phase 3 trial of the duration of elective androgen deprivation in locally advanced prostate cancer. I Clin Oncol 2008:26:2497-2504. https://doi.org/10.1200/JC0.2007.14.9021

4. Nickel JC, Tripp DA, Pontari M, et al. Psychosocial phenotyping in women with intersititial cystitis/painful bladder syndrome: A case control study. J Urol 2010;183:167-72. https://doi.org/10.1016/i. juro.2009.08.133

5. Sharifi N, Gulley JL, Dahut WL. Androgen-deprivation therapy for prostate cancer. JAMA 2005;294:238-44. https://doi.org/10.1001/jama.294.2.238

6. Dinh KT, Reznor G, Muralidhar V, et al. Association of androgen-deprivation therapy with depression in localized prostate cancer. J Clin Oncol 2016;34:1905-12. https://doi.org/10.1200/JC0.2015.64.1969

7. Herr HW, O'Sullivan M. Quality of life of asymptomatic men with non-metastatic prostate cancer on androgen-deprivation therapy. J Urol 2000;163:1743-6. https://doi.org/10.1016/S0022 $5347(05) 67533-7$

8. Radloff L. The CES-D scale: A self-report depression scale for research in the general population. Appl Psychol Meas 1977;1:385-401. https://doi.org/10.1177/014662167700100306

9. Lewinsohn PM, Seeley JR, Roberts RE, et al. Centre for Epidemiologic Studies Depression Scale (CES-D) as a screening instrument for depression among community-residing older adults. Psychology and Aging 1997;12:277-87. https://doi.org/10.1037/0882-7974.12.2.277

10. Ware J Jr, Kosinski M, Keller SD. A 12-item short-form health survey: Construction of scales and preliminary tests of reliability and validity. Med Care 1996;3:220-33. https://doi.org/10.1097/00005650199603000-00003
11. Cheack-Zamora NC, Wyrwich KW, McBride TD. Reliability and validity of the SF012 in the medical expenditure parnel survey. Qual Life Res 2009;18:727-35. https://doi.org/10.1007/s1 1136-009-9483-1

12. Spielberger CD, Gorsuch RL, Lushene RE. Manual for the State-Trait Anxiety Inventory; 1970.

13. Sullivan MJ, Bishop SR, Pivik J. The Pain Catastrophizing Scale: Development and validation. Psychol Assessment 1995;7:524-32. https://doi.org/10.1037/1040-3590.7.4.524

14. Zimet GD, Dahlem NW, Zimet SG, et al. The Multidimensional Scale of Perceived Social Support. J Pers Assess 1988:52:30-41. https://doi.org/10.1207/s15327752ipa5201_2

15. Vreeburg SA, Hoogendijk WJ, van Pelt J, et al. Major depressive disorder and hypothalamic-pituitaryadrenal axis activity: Results from a large cohort study. Arch Gen Psychiatry 2009;66:617-26. https://doi.org/10.1001/archgenpsychiatry.2009.50

16. Little R, Yau L. Intent-to-treat analysis for longitudinal studies with dropouts. Biometrics 1996;52:1324-33. https://doi.org/10.2307/2532847

17. Hsu B, Cumming RG, Blyth FM, et al. Longitudinal and cross-sectional relationships of circulating reproductive hormone levels to self-rated health and health-related quality of life in community-dwelling older men. J Clin Endocrinol Metab 2014;99:1638-47. https://doi.org/10.1210/ic.2013-3984

18. Curtis R, Groarke A, Sullivan F. Stress and self-efficacy predict psychological adjustment at diagnosis of prostate cancer. Sci Rep 2014;4:5569. https://doi.org/10.1038/srep05569

19. Llorente MD, Burke M, Gregory GR, et al. Prostate cancer: A significant risk factor for late-life suicide. Am J Geriatric Psychiatry 2005;13:195-201. https://doi.org/10.1097/00019442-200503000-00004

20. Kunkel EJS, Bakker JR, Myers RE, et al. Biopsychosocial aspects of prostate cancer. Psychosomatics 2000;41:85-94. htrps://doi.org/10.1176/appi.psy.41.2.85

21. Lintz K, Moynihan C, Steginga S, et al. Prostate cancer patients' support and psychological care needs: Survey from a non-surgical oncology clinic. Psychooncology 2003;12:769-83. https://doi.org/10.1002/pon.702

22. Hopko DR, Armento MEA, Robertson SMC, et al. Brief behavioural activation and problem-solving therapy for depressed breast cancer patients: Randomized trial. J Consult Clin Psychol 2011;79:834-49. https://doi.org/10.1037/a0025450

23. Alibhai SM, Breunis $\mathrm{H}$, Timilshina $\mathrm{N}$, et al. Impact of androgen-deprivation therapy on physical function and quality of life in men with non-metastatic prostate cancer. J Clin Onc 2010;28:5038-45. https://doi.org/10.1200/JC0.2010.29.8091

Correspondence: Dr. Dean A. Tripp, Departments of Psychology, Anesthesiology and Urology, Queen's University, Kingston, ON, Canada; dean.tripp@queensu.ca

\section{Introducing the Canadian Undergraduate Urology Curriculum (CanUUC)!}

The last 40 years has seen a significant decline in formal undergraduate urologic education throughout Canada. Given the large burden of urologic disease in general medical practice we felt it was imperative that core aspects of urology are preserved as part of undergraduate medical education. With this in mind the Canadian undergraduate urology curriculum (CanUUC) initiative was born. CanUUC was formed with urologic representation from most of the medical schools throughout Canada. This committee has worked toward creating and revising a uniquely Canadian undergraduate urology curriculum focused on forming a "urologically well-informed" medical school graduate.

Our goal is to have a multi-faceted online curriculum that can be easily applied to any situation or site throughout Canada for teaching on the ward, clinic, operating room or at home. Our committee has developed ten PowerPoint seminars covering 10 core aspects of urology including Benign Prostatic Hyperplasia, Prostate Cancer, Urinary Tract Infection, Hematuria, Incontinence, Pediatric Urology, Uro-trauma, Stone Disease, Erectile Dysfunction and Scrotal Conditions. We have also created a series of enhanced podcasts to further compliment these topics and added videos on how to insert a urethral catheter and how to perform a genitourinary examination.

Please feel free to use this curriculum as you see fit. We hope that it will enhance your understanding of Urology, a vibrant and important medical specialty. The link to the curriculum is: https://www.cua.org/en/canucc 